\title{
Erratum to: Infrasound and seismic detections associated with the 7 September 2015 Bangkok fireball
}

Corentin Caudron ${ }^{1 *+}$ (D) , Benoit Taisne ${ }^{1,2+}$, Anna Perttu $^{1 \dagger}$, Milton Garcés ${ }^{3 \dagger}$, Elizabeth A. Silber ${ }^{4+}$

and Pierrick Mialle ${ }^{5+}$

\section{Erratum to: Geosci. Lett. (2016) 3:26 \\ DOI 10.1186/s40562-016-0058-z}

After publication of the original article [1], the authors found the following sentence was missing from the Acknowledgements:

"This work comprises Earth Observatory of Singapore contribution 130. This research is supported by the National Research Foundation Singapore and the Singapore Ministry of Education under the Research Centres of Excellence initiative."

\begin{abstract}
Author details
${ }^{1}$ Earth Observatory of Singapore, 50, Nanyang Ave, Singapore 639798, Singapore. ${ }^{2}$ Asian School of the Environment, Nanyang Technological University, 50 Nanyang Avenue, Block N2-01a-15, Singapore 639798, Singapore. ${ }^{3}$ Infrasound Laboratory, Hawaii Institute of Geophysics and Planetology, School of Ocean and Earth Science and Technology, University of Hawaii, Manoa, Honolulu, USA. ${ }^{4}$ Department of Physics and Astronomy, Centre for Planetary Science and Exploration, University of Western Ontario, London, ON N6A 3K7, Canada. ${ }^{5}$ Preparatory Commission for the Comprehensive Nuclear Test-Ban Organization, Vienna, Austria.
\end{abstract}

The online version of the original article can be found under doi:10.1186/s40562-016-0058-z.

Received: 8 September 2016 Accepted: 8 September 2016

Published online: 22 September 2016

\section{Reference}

1. Caudron C, Taisne B, Perttu A, Garcés M, Silber EA, Mialle P (2016) Infrasound and seismic detections associated with the 7 September 2015 Bangkok fireball. Geosci. Lett. 3:26. doi:10.1186/s40562-016-0058-z

*Correspondence: corentin.caudron@gmail.com

${ }^{\dagger}$ All the authors contributed equally

${ }^{1}$ Earth Observatory of Singapore, 50, Nanyang Ave, Singapore 639798,

Singapore

Full list of author information is available at the end of the article 